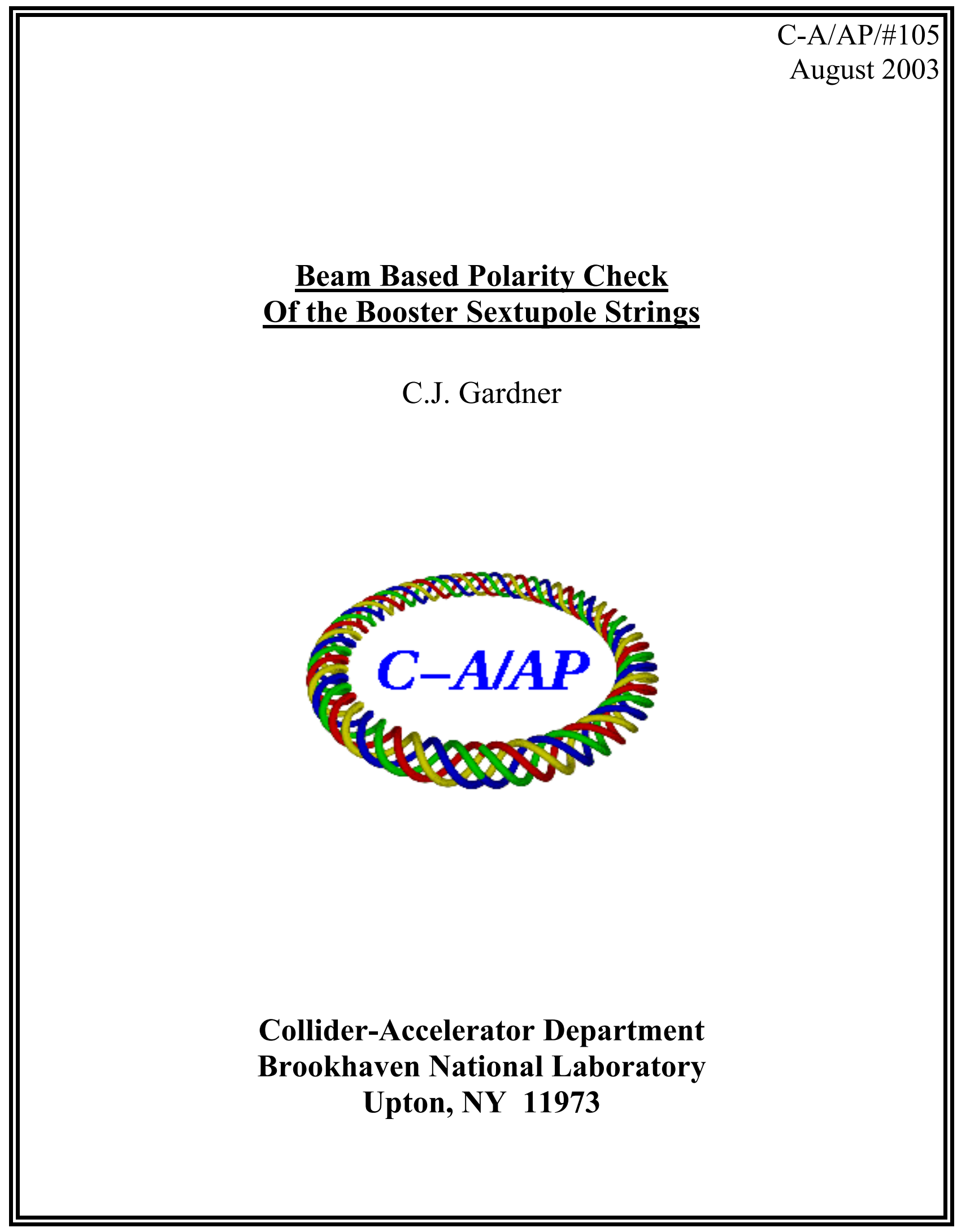




\title{
Beam Based Polarity Check of the Booster Sextupole Strings
}

\author{
C.J. Gardner
}

August 11, 2003

During the summer of 2002, the sextupoles in Booster were reconfigured into a new set of strings to allow for the resonant extraction of beams to the Booster facility NSRL (National Space Radiation Laboratory). There are all together four strings which are called the Horizontal, Vertical, C, and $\mathrm{F}$ strings. The corresponding currents are $I_{H}, I_{V}, I_{C}$ and $I_{F}$. A complete description of the strings and their programming is given in Ref. [1]. We report here on a set of beam based measurements which verify the polarities of the strings.

\section{Method}

The basic idea is to observe how the various strings affect the machine chromaticity. Measurements were made with low-intensity proton beam in Booster during the FY2003 polarized proton run. The beam was kicked with the horizontal tune meter kicker at a given time during the magnetic cycle and the resulting coherent betatron oscillations were observed at a horizontal BPM (Beam Position Monitor). (It would have been desirable to observe oscillations also at a vertical BPM, but only one vertical BPM is available and it was not working.) Turn-by-turn sum and difference signals from the horizontal BPM were captured on an oscilliscope and analyzed by the computer program called PIP [2]. The analysis yields several parameters of the coherent oscillations including the amplitude $A$, the horizontal tune $Q_{H}$, and the tune spread $\Delta Q_{H}$ responsible for the decay of the coherence. In terms of the normalized horizontal chromaticity, $C_{H}$, the observed tune spread is given by

$$
\frac{\Delta Q_{H}}{Q_{H}}=\left|C_{H}\right|\left(\frac{\Delta p}{p}\right)
$$


where $\Delta p$ is the momentum spread of the beam and $p$ is the mean momentum. With zero current in all of the sextupole strings, $C_{H}$ will be negative and $\Delta Q_{H}$ will be nonzero. One can then verify the polarities of the strings by determining the currents necessary to move $C_{H}$ and $\Delta Q_{H}$ toward zero.

\section{Results}

Turn-by-turn data were obtained from (horizontal) PUE B4 with the tune meter kicker set to kick the beam at $55 \mathrm{~ms}$ from BT0. Here the programmed magnetic field was $0.273 \mathrm{~T}$. Assuming radius of curvature $\rho=13.8656 \mathrm{~m}$ then gives magnetic rigidity $B \rho=3.7853 \mathrm{Tm}$ and proton kinetic energy $W=534 \mathrm{MeV}$ at the time of the kick.

Figure 1 shows the position versus turn and fitted curve obtained with the currents in all of the sextupole strings set to zero $\left(I_{H}=I_{V}=I_{C}=I_{F}=0\right)$. This gives $C_{H}=-1.6$ in the Booster Chrom Control program. The fitted parameters from the PIP program are $Q_{H}=4.7435(15), A=3.12(15) \mathrm{mm}$, and $\Delta Q_{H}=6.61(75) \times 10^{-3}$.

For the data of Figure 2, $I_{H}$ was adjusted to make $C_{H}=0$ in the Chrom Control program. All other currents were set to zero. The fitted parameters from the PIP program are $Q_{H}=4.7411(11), A=3.56(14) \mathrm{mm}$, and $\Delta Q_{H}=3.0(1.1) \times 10^{-3}$. Here we see that the tune spread is significantly reduced. This verifies that the horizontal string has the correct polarity. (An increase in $\Delta Q_{H}$ would have indicated that the horizontal string has the opposite polarity.)

With $I_{H}, I_{C}$, and $I_{F}$ set to zero, $I_{V}$ was adjusted to make $C_{H}=-2.4$ in the Chrom Control program. This gives fitted parameters

$Q_{H}=4.7465(16), A=3.00(16) \mathrm{mm}$, and $\Delta Q_{H}=8.04(74) \times 10^{-3}$. Here we see an increase in $\Delta Q_{H}$ as expected. This verifies that the vertical string has the correct polarity.

With $I_{H}$ and $I_{V}$ set to zero, $I_{C}$ and $I_{F}$ were set to be equal and adjusted to make $C_{H}=0$ in the Chrom Control program. This gives fitted parameters $Q_{H}=4.7331(12), A=3.19(14) \mathrm{mm}$, and $\Delta Q_{H}=1.6(2.1) \times 10^{-3}$. Here we see that the tune spread is significantly reduced, which verifies that the $\mathrm{C}$ and $\mathrm{F}$ strings have the correct polarity.

With $I_{H}$ and $I_{V}$ set to zero, $I_{C}$ and $I_{F}$ were also adjusted to make $C_{H}=-2.1$ in the Chrom Control program. This gives fitted parameters 
$Q_{H}=4.7365(19), A=3.01(17) \mathrm{mm}$, and $\Delta Q_{H}=10.0(8) \times 10^{-3}$. As expected, $\Delta Q_{H}$ increases significantly which again verifies that the $\mathrm{C}$ and $\mathrm{F}$ strings have the correct polarity.

\section{Wiring Diagrams}

Wiring diagrams for the four strings are shown in Figures $\mathbf{3}, \mathbf{4}$, and $\mathbf{5}$. These are described in detail in Ref. [1]. The polarity conventions are given in Ref. [3].

\section{References}

[1] C.J. Gardner, "Programming the New Sextupole Strings in Booster", C-A/AP Note 96, May 2003

[2] C.J. Gardner, L.A. Ahrens, N. Williams, "Turn-by-Turn Analysis of Proton and Gold Beams at Injection in the AGS Booster", Proceedings of the 1999 Particle Accelerator Conf., PAC-99, New York, N.Y., March 29-April 2, 1999

[3] E. Bleser, "Booster Polarity Standards", Booster Technical Note 180, October 30, 1990 


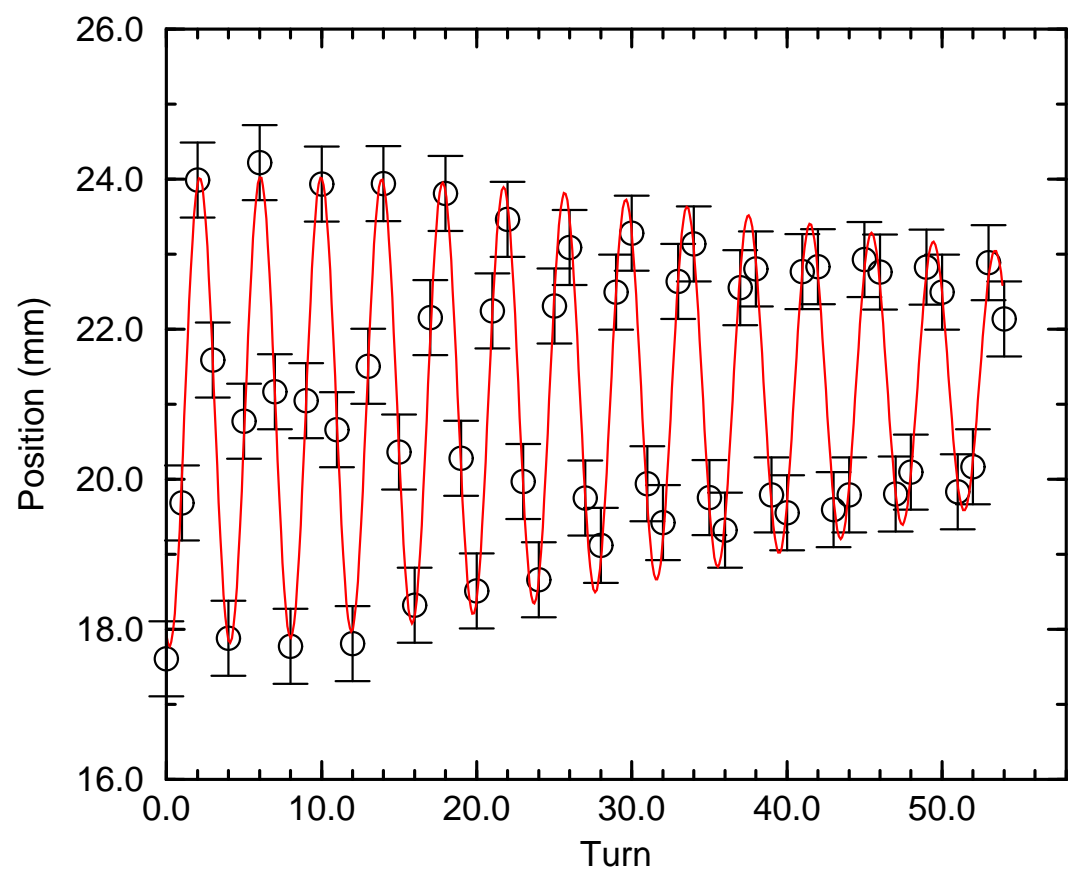

Figure 1: Turn-by-turn data and fitted curve obtained with $I_{H}=I_{V}=$ $I_{C}=I_{F}=0$ in the Chrom Control program. This gives $C_{H}=-1.6$ in the program. Among the fitted parameters from the PIP program are $Q_{H}=$ 4.7435(15), $A=3.12(15) \mathrm{mm}$, and $\Delta Q_{H}=6.61(75) \times 10^{-3}$. 


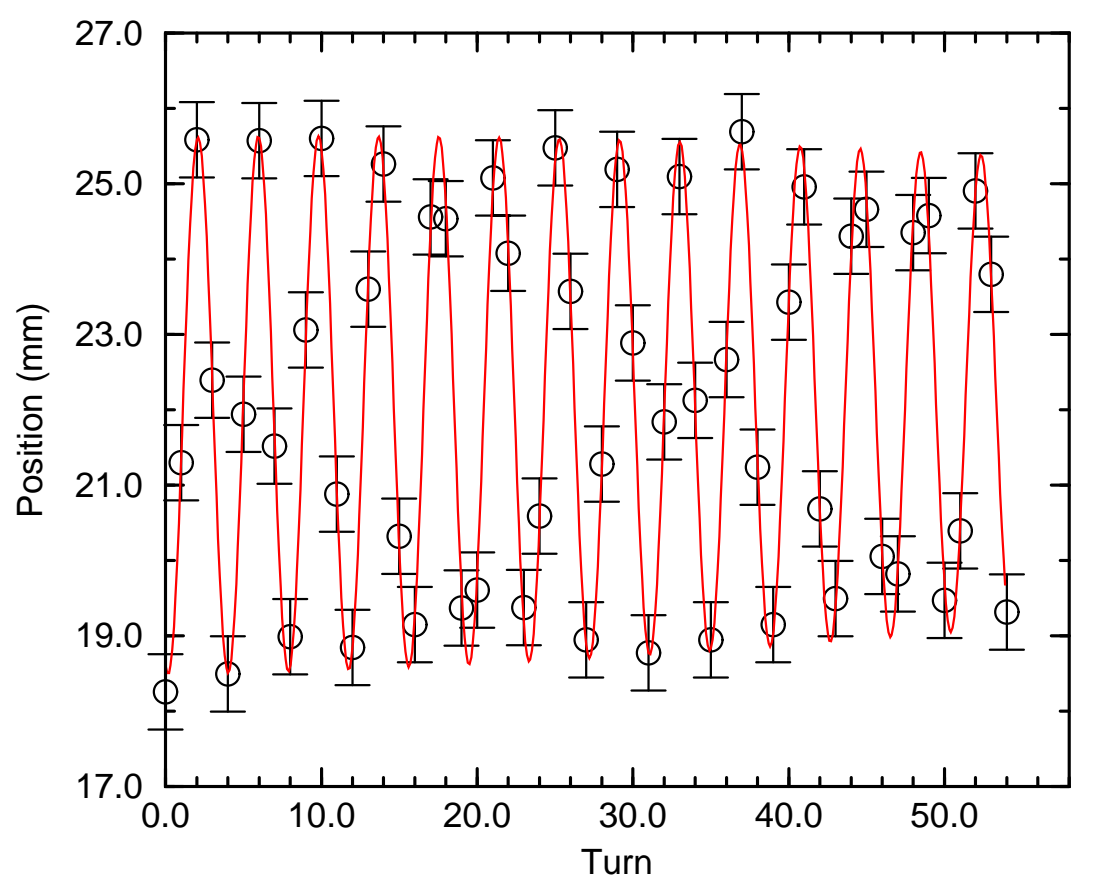

Figure 2: Turn-by-turn data and fitted curve obtained with $I_{V}, I_{C}$, and $I_{F}$ set to zero and $I_{H}$ adjusted to make $C_{H}=0$ in the Chrom Control program. Among the fitted parameters from the PIP program are $Q_{H}=4.7411(11)$, $A=3.56(14) \mathrm{mm}$, and $\Delta Q_{H}=3.0(1.1) \times 10^{-3}$. 


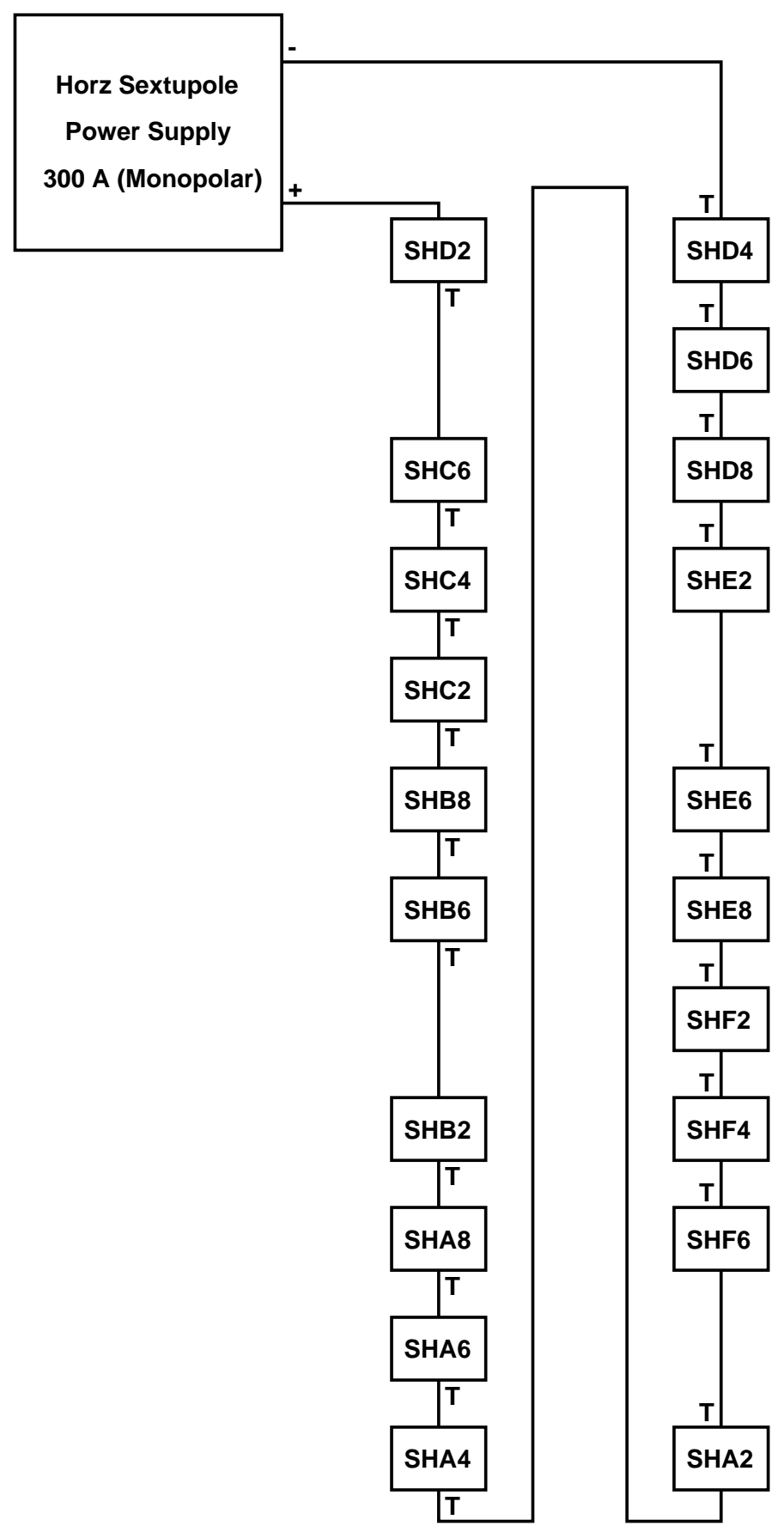

Figure 3: Wiring Diagram for the Horizontal Sextupole String. Here, in accordance with the definitions of Ref. [3], the monopolar power supply puts the sextupoles in "B" polarity. This increases the horizontal chromaticity. 


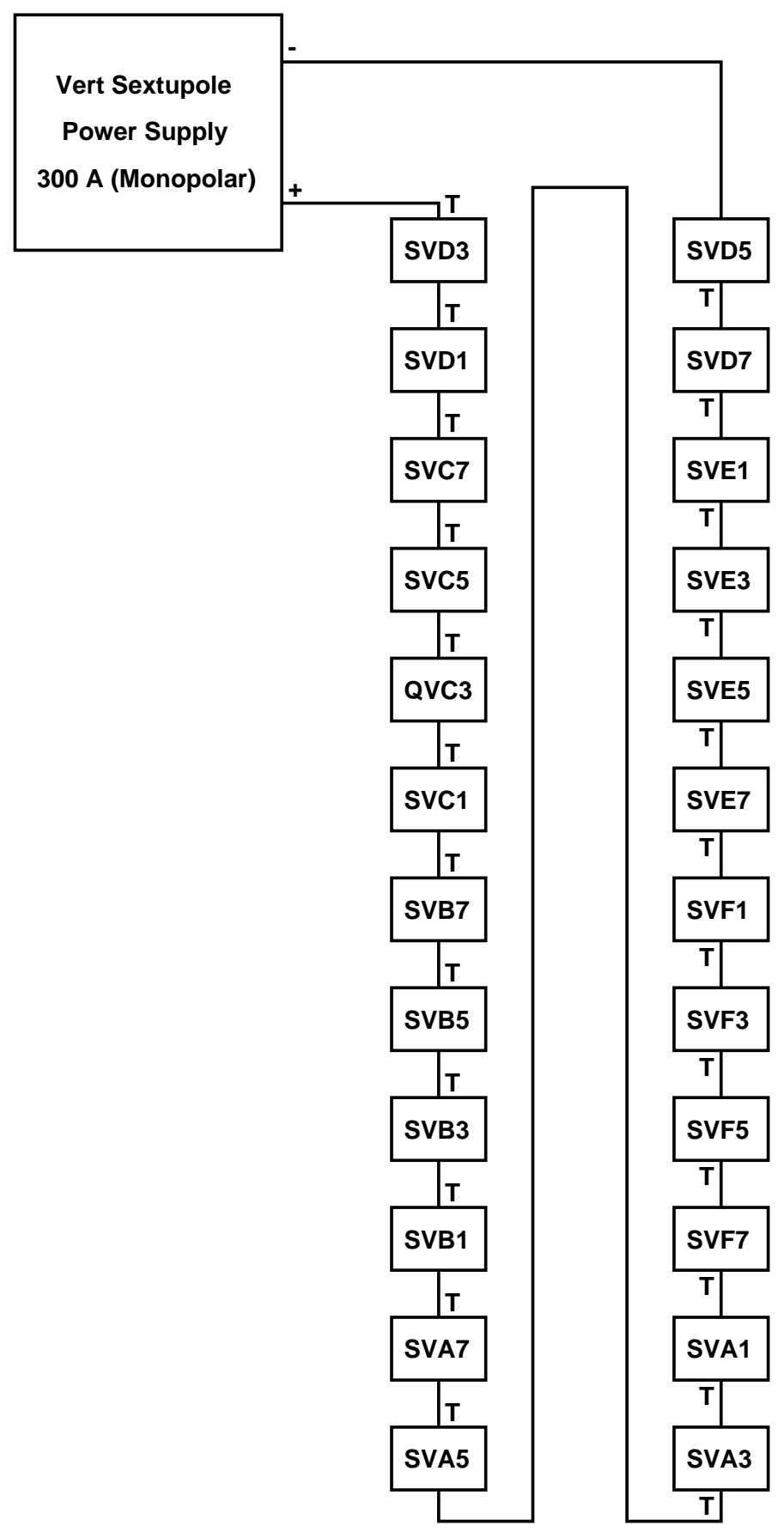

Figure 4: Wiring Diagram for the Vertical Sextupole String. Here, in accordance with the definitions of Ref. [3], the monopolar power supply puts the sextupoles in "A" polarity. This increases the vertical chromaticity. 

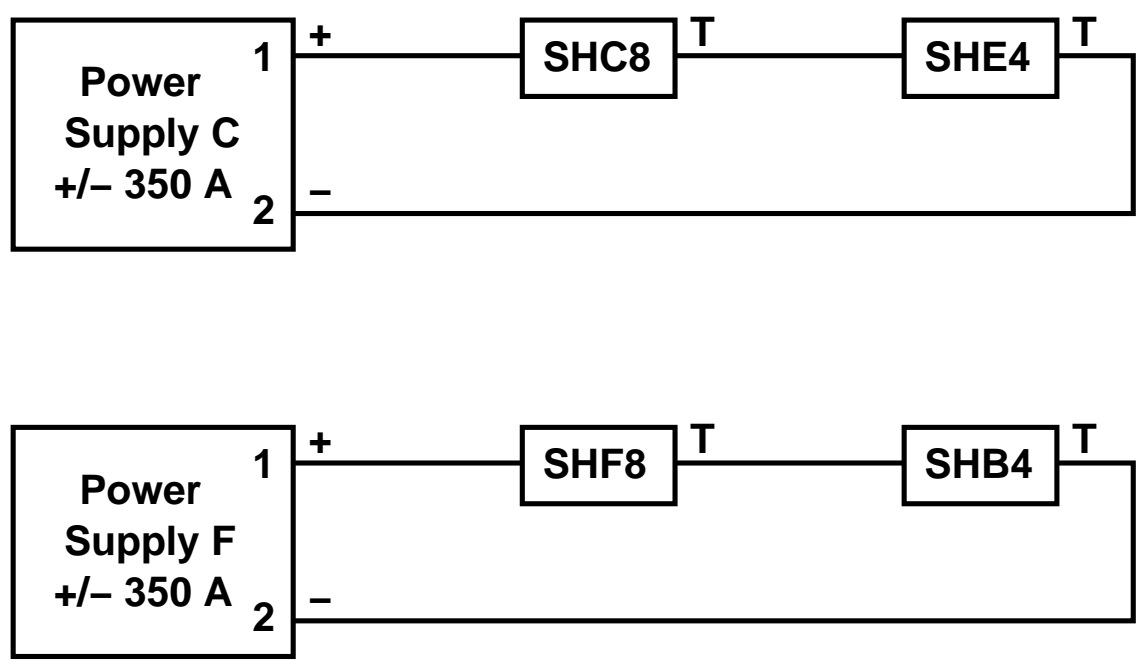

Figure 5: Wiring Diagram for the $\mathrm{C}$ and $\mathrm{F}$ Strings. In accordance with the conventions of Ref. [3], a positive reference at the power supply input produces a positive current out of the terminal labeled " 1 ". This puts the sextupoles in the strings in "B" polarity. The $Q_{H}=4+1 / 3$ resonance is excited by powering the two strings with opposite polarity. Note that in the control system, power supplies $\mathrm{C}$ and F are called "b-sxr1-ps" and "b-sxr2-ps" respectively. 